\title{
Tutela jurisdiccional efectiva y la ausencia de regulación de un derecho constitucional para redireccionar el gasto público: El caso del Estado de Jalisco, México
}

\author{
Effective jurisdictional protection and the absence of regulation of a constitutional \\ right to redirect public spending: The case of the State of Jalisco, Mexico
}

\author{
Héctor Iván del Toro Ríos (iD) \\ Universidad de Guadalajara, México \\ Hiram Zambrano Brambila (iD \\ Universidad de Guadalajara, México \\ Ricardo Ruiz García (iD \\ Universidad de Guadalajara, México
}

RESUMEN La Constitución, como texto normativo fundamental en la vida de un país, es el ideal para lograr y permitir el pleno ejercicio de la libertad y dignidad de los individuos, grupos y clases sociales, bajo un marco de igualdad. Al respecto, esta investigación desarrolla una crítica ante la ausencia de un derecho constitucional, que faculte al ciudadano para redireccionar el gasto público, y ante cómo los derechos públicos subjetivos, como en el caso del establecido en el principio de tutela jurisdiccional efectiva, pueden ayudar a alcanzar estos ideales ante la nula intervención ciudadana directa en la toma de decisiones del país frente a la vigente realidad histórica, política, económica y social en que vivimos en México.

PALABRAS CLAVE Tutela jurisdiccional efectiva, derecho, gasto público, Constitución, intervención ciudadana.

ABSTRACT The Constitution, as a fundamental regulatory text in a country's life, is ideal for achieving and allowing the absolute freedom and dignity of individuals, groups and social classes under equal conditions. In that regard the current research develops a criticism in the absence of a constitutional right that empowers the citizen to reroute the public expenditure, as well as subjective public rights, like the one established in the principle of effective judicial protection which can help accomplishing such ideals before the nondirect citizen involvement, in the decision-making process at the current historical, political, economic and social reality that we are living in Mexico. 
KEYWORDS Effective judicial protection, right, public spending, Constitution, citizen intervention.

\section{Introducción}

A través de este trabajo, y en el marco de los principios constitucionales de la imposición y la justicia tributaria, se desarrolló un análisis crítico en el que los autores señalamos la ausencia de un derecho constitucional que faculte al ciudadano para redireccionar el gasto público. Esto, bajo un análisis de una serie de antecedentes de ineficiencia en la ejecución del gasto en México y el ejemplo de cómo la tutela jurisdiccional efectiva puede incidir en su evolución.

Esta investigación consta de ocho apartados, incluida esta introducción. En primera instancia encontraremos el planteamiento del problema, el cual, de forma medular, establece la ausencia de un derecho constitucional que permita al ciudadano, en casos específicos, el redireccionamiento del gasto público ante situaciones de causa de fuerza mayor $o$ ante escenarios en los que las decisiones del ejercicio de ese gasto puedan ser inconvenientes.

Por otra parte, este trabajo traza como objetivo que la problemática expuesta con antelación impide a los ciudadanos ejercer controles democráticos (por ejemplo, en un momento en el que la crisis mundial por el covid-19 ha generado un aumento importante de los montos de deudas de los gobiernos nacionales), y si de ese modo el derecho público subjetivo, plasmado en el principio de la tutela jurisdiccional efectiva, es la alternativa para mutar a este derecho ciudadano o conformarlo.

Para esquematizar esta problemática, será necesario establecer los antecedentes de lo que hasta la actualidad ha sido parte de la ineficiencia en el gasto y señalar como, en la praxis, tuvo que llegar una pandemia a nivel mundial para que el poder judicial fuera el contrapeso que el ciudadano necesita para hacer valer sus derechos públicos subjetivos, como la tutela jurisdiccional efectiva.

Para concluir el desarrollo del trabajo, el lector encontrará una serie de razonamientos con los cuales los autores determinamos la ausencia de un derecho constitucional que permita el redireccionamiento del gasto público en casos específicos, en un análisis y crítica correlacional, donde se infiere una trasgresión al principio de igualdad establecido en el artículo 1 de la Constitución y la rectoría del desarrollo nacional dispuesta en el artículo 25.

\section{Planteamiento del problema}

México es una República representativa, democrática, laica y federal, compuesta por Estados libres y soberanos, como lo establece la Constitución Política mexicana (CPEUM), ordenamiento máximo normativo de la vida política, social y económica del país. Esto, en sus aspectos rectores establecidos en contraprestación de la exacción a 
la población con base al cumplimiento de la obligación establecida en la fracción cuarta de su artículo 31:

Los impuestos, desde esa perspectiva, fueron considerados como una forma de explotación de los ciudadanos con el pretexto o la promesa de que, a cambio de la exacción, el Estado haría algo por el bien común, y no solo financiaría sus propios ensueños (la guerra, alguna empresa de conquista o, de plano, aprovechando las circunstancias de indiferencia e ignorancia, llevar a cabo una abierta asignación de privilegios) (Arteaga Mac Kinney, 2010: 103).

En relación con esto, otra obligación ineludible de los mexicanos es la establecida con la República y su defensa, como lo dispone el párrafo IV del artículo 35 de la Ley Fundamental, «Tomar las armas en la Fuerza Armada permanente o en los cuerpos de reserva, para la defensa de la República y de sus instituciones, en los términos que prescriben las leyes». Si este texto se adaptase pensando en la realidad actual, debería indicar que esas armas serían mayores facultades y dinamismo a la ciudadanía.

En otras palabras, la importancia de contribuir constituye un mandato por el cual la persona sostiene, en la medida de sus posibilidades, las finanzas públicas, obligación que incluso podría equipararse a la diversa prevista y ya citada en el artículo 35, fracción IV CPEUM, que si bien refiere a tomar las armas en defensa de la República, con mayor razón se justifica el sacrificar una parte de los patrimonios privados en beneficio del país y el insigne cuidado del presupuesto.

Es por esto que esta investigación se contextualiza a la ineficiencia en la ejecución del gasto público en México ante el mandato constitucional otorgado, un mandato de desempeño, el cual parecería que no implica la obligación de eficacia; o si la representatividad de los diputados satisface al ciudadano, en el entendido de que no existe un recurso o derecho constitucional que faculte a este para encauzar la redirección de este gasto bajo circunstancias particulares.

Aseveramos lo dicho, ya que algunos de los recursos existentes para el ciudadano son, por ejemplo, las responsabilidades administrativas, en consecuencia del desapego al Estado de derecho y en perjuicio de la ciudadanía, o la responsabilidad patrimonial del Estado, la cual atiende a una consecuencia, pero ahora de la actividad irregular administrativa, o bien, el recurso previsto en la Ley de Coordinación Fiscal en su artículo 11-A.

Es este último, por ejemplo, un recurso de inconformidad para los ciudadanos que resulten afectados por incumplimiento de las disposiciones del Sistema Nacional de Coordinación Fiscal y de las de coordinación en materia de derechos, los cuales podrán presentar, en un ámbito de recaudación y distribución, con fundamento en el convenio de adhesión celebrado entre la federación y los Estados, como señala Lidana Montoya Fernández. ${ }^{1}$

\footnotetext{
1. Lidana Montoya Fernández, «Las participaciones federales: El resorte de la (creciente) deuda pública en los estados», Derecho en Acción, 7 de abril de 2016, disponible en bit.ly/2LZjugB.
} 
Dichos recursos, en general, atienden a resarcir un daño o facultan al ciudadano para actuar al nivel de la autoridad responsable, por lo que los suscritos señalamos, en esta investigación, que el recurso propuesto, a diferencia de los anteriores, podría servir como contrapeso en la toma de decisiones que se suscitan en perjuicio a la ciudadanía y permitiría a los ciudadanos actuar en momentos específicos o que sean causa de fuerza mayor, como una obligación constitucional.

Con base en lo anterior, en el constructo de esta investigación, surge el principio de la tutela jurisdiccional efectiva, como ese derecho público subjetivo incorporado en la esfera jurídica de todo gobernado. Desde nuestro enfoque, servirá de sustento para sugerir el establecimiento de mecanismos y/o desarrollar la posibilidad de un recurso judicial que permita al ciudadano oponerse formal e institucionalmente a ineficiencias en el ejercicio del gasto público, según se explicará.

Por lo anterior, nos preguntamos: $¿$ Se cumple con el principio de tutela jurisdiccional efectiva ante la ausencia de un derecho constitucional que faculte al ciudadano para redireccionar el gasto público, en los casos en los que la ineficiencia de su ejercicio demuestra un notorio despilfarro? Actualmente, este planteamiento se pone en la palestra como un tema tanto contingente como pertinente dentro de los derechos fundamentales y las obligaciones de los ciudadanos.

La problemática expuesta demuestra la necesidad de crear instrumentos legales, procesales y formales al alcance de cualquier persona en busca de reconducir el debido ejercicio del gasto público, no en sus fines decretados en el presupuesto respectivo, sino en los resultados que revela su ejercicio y en las expectativas razonables que surgen a partir de esos resultados.

Asimismo, dichos instrumentos permitirían democratizar y controlar los recursos presupuestales al menos en el caso de Jalisco, en cuya experiencia empírica, real e histórica se revelan hechos específicos que nos orientan a plantear esta necesidad de actualizar la esencia de nuestra Constitución en materia de gasto público y de la participación ciudadana, que proponga, además, un nuevo modelo de nación bajo una nueva perspectiva jurídica.

\section{Objetivo}

A partir del problema expuesto, el objetivo de esta investigación será presentar un análisis crítico sobre la ausencia de un derecho constitucional, que faculte al ciudadano para redireccionar el gasto público en los casos en los que, de forma específica, proceda. Acorde a esto, la premisa será si el principio de la tutela jurisdiccional efectiva como derecho público subjetivo (derecho a la administración de justicia) puede ser una alternativa ante dicha ausencia.

El párrafo anterior debe entenderse a partir de la idea de la justicia tributaria y el destino del gasto público como un elemento indispensable para operacionalizar la justicia como objetivo de cualquier estado normativo en la vida social y los esenciales para que esta se cumpla, bajo los principios de igualdad del artículo 1 de la Ley Fundamental 
y la tutela del Estado, en relación con la rectoría de desarrollo social y el bienestar de sus ciudadanos del artículo 25 de la Constitución.

Ya lo ha expresado la Suprema Corte de Justicia de la Nación al mencionar que «una contribución no solo puede tener como finalidad la recaudación, sino que puede servir como instrumento para alcanzar otros objetivos, a lo cual se le denomina como la imposición de un gravamen con fines extrafiscales», ${ }^{2}$ así como «la estabilidad de las finanzas públicas exige el uso eficiente del ingreso, el gasto y la deuda pública». ${ }^{3}$

Así, se reitera el objetivo de esta investigación, que es exponer un análisis crítico sobre la ausencia de un derecho constitucional que faculte al ciudadano para redireccionar el gasto público en los casos en que sea necesario, con el fin de plantear la necesidad ciudadana de que se dinamice su actuación en la toma de decisiones extraordinaria ante la ineficiencia del gasto público en México para casos particulares e, incluso, la ausencia de este en la experiencia latinoamericana y sus esbozos ante la búsqueda de una mayor participación ciudadana en las decisiones del gasto.

\section{Antecedentes}

En relación con lo que hasta al momento se ha expuesto, el doctor Juan Carlos de Obeso Orendain (2020) señala, desde una perspectiva de justicia tributaria completa o desde la nuestra, en una arista adjetiva a través de una tutela jurisdiccional efectiva, que dicha facultad, hasta el momento, es exclusiva de los poderes políticos y no del ciudadano.

De igual forma, la naturaleza social del principio de vinculación al gasto público detona una problemática concreta, consistente en que este, a diferencia del resto de los principios de justicia tributaria reconocidos en el artículo 31, fracción IV, de la Constitución Política mexicana, no goza de una amplia producción normativa, lo que se traduce en la ausencia de una infraestructura teórica-jurídica que les permita a los operadores jurídicos limitar la libertad de configuración presupuestaria con que gozan los poderes políticos (De Obeso Orendain, 2020).

Ante la evidencia histórica mostrada en los hechos sobre finanzas públicas, (específicamente del Estado de Jalisco) por ejemplo, en algunos casos no se cumplió con la rectoría del desarrollo nacional dispuesta en el artículo 25 Constitucional, ni con el artículo 1, tercer párrafo del mismo ordenamiento, en el que todas las autoridades, en el ámbito de sus competencias, tienen la obligación de proteger y garantizar los derechos humanos:

2. Sentencia ejecutoria de la Suprema Corte de Justicia de la Nación en Amparo en Revisión 815/2015, Agroquímicos Rivas, S.A. DE C.V, del 20 de marzo de 2019. Cuatro votos de los ministros Alberto Pérez Dayán, Eduardo Medina Mora I., José Fernando Franco González Salas y Javier Laynez Potisek (ponente). Secretario: Octavio Joel Flores Díaz. Semanario Judicial de la Federación, Décima Época, Segunda Sala. Publicado el 11 de octubre de 2019, disponible en bit.ly/38Dpc8J.

3. Lidana Montoya Fernández, «Las participaciones federales: El resorte de la (creciente) deuda pública en los estados», Derecho en Acción, 7 de abril de 2016, disponible en bit.ly/2LZjugB. 
Desde una perspectiva sociológica, Hauke Brunkhorst: solo a través de una verdadera garantía democrática de inclusión de todos los ciudadanos, nosotros podemos aspirar a un modelo de Estado liberal que esté, a la vez, ligado a la primacía de lo justo sobre el bien y sea aceptable también por parte de aquellos ciudadanos que se identifican en identidades ético-comunitarias enraizadas en valores fuertes (Zoffoli, 2010: 80).

Es decir, el Estado velará por la estabilidad de las finanzas públicas y del sistema financiero para coadyuvar a generar condiciones favorables para el crecimiento económico y el empleo. La premisa anterior no solo alude al Plan Nacional de Desarrollo, sino también a los planes estatales y municipales, que deberán observar dicho principio en los extremos de los dispuestos en el artículo 25 CPEUM, y el desarrollo nacional, propiamente:

Garantizar que este sea integral y sustentable, que fortalezca la Soberanía de la Nación y su régimen democrático y que, mediante la competitividad, el fomento del crecimiento económico y el empleo, y una más justa distribución del ingreso y la riqueza, permita el pleno ejercicio de la libertad y la dignidad de los individuos, grupos y clases sociales, cuya seguridad protege esta Constitución (Constitución Política de los Estados Unidos Mexicanos, 1917: artículo 25, inciso 1). ${ }^{4}$

Lo anterior, también derivado de una Constitución que, desde nuestro punto de vista, no evoluciona de forma integral y, sin esa evolución uniforme, no se adapta a la realidad histórica ni a las necesidades de los ciudadanos actuales, como lo es el crear un recurso sustentado en un derecho constitucional que permita el redireccionamiento del gasto ante circunstancias específicas, como su ineficiencia o deficiente planeación:

Condiciones de eficacia aparte, la Constitución aprobada el 31 de enero de 1917 y la actual es y no es la misma. Lo es si la entendemos a partir de sus funciones en el orden jurídico, o la autorreferencia en los procesos de reforma o adición a sus preceptos originarios. Desde esos dos valores estrictamente normativos, podemos aceptar que la Constitución de entonces y la de ahora son la misma. Desde un punto de vista histórico-político, también que tendríamos que aceptar la continuidad. En los últimos cien años no se ha producido un movimiento de tal magnitud que haya quebrado la línea de la continuidad política que generó y mantiene el texto originario (Roldán Xopa, 2018). ${ }^{5}$

Prueba de esta ineficiencia del gasto, la omisión de nuestros legisladores jaliscienses, así como de las Auditorías Superiores, de la Federación y del Estado, que han permitido, en algunos casos, que los proyectos de inversión pública resulten más costosos y que no se concreten en la temporalidad de determinada cuenta pública, como el caso

4. Para más información, véase el texto oficial actualizado el 8 de mayo de 2020, disponible en bit. ly/2WLpkxJ.

5. Comentario emitido por el, hasta ese momento, ministro de la Suprema Corte de Justicia de la Nación, el licenciado José Ramón Cossío Díaz, en la presentación del libro citado. 
Arcos del Milenio, que debió entregarse en 2000 por el H. Ayuntamiento de Guadalajara de Jalisco.

Por lo tanto, al observar a las Auditorías Superiores, el Poder Legislativo o la ausencia de un recurso específico, no se ha logrado contener este cúmulo de decisiones, por lo que, ante la obligación constitucional ciudadana plasmada en su artículo 35, párrafo IV, la defensa de la República debería ser a partir de una arista económica, en el cuidado que se tenga en el ordenamiento un recurso que posibilite el redireccionamiento del gasto en situaciones específicas, facultando al individuo para su interposición.

$\mathrm{Al}$ respecto, coincidimos también con De Obeso Orendain (2020) con que tanto los derechos civiles y políticos o el otro eje de los derechos económicos, sociales y culturales no son infranqueables ni están construidos sobre una barrera rígida, que impida a la actividad jurisdiccional satisfacer necesidades básicas de los individuos a través de mecanismos propios del Estado liberal, como en el caso del gasto público.

\section{Acciones propuestas por los autores}

Aunado a las observaciones expuestas con respecto a la ineficiencia del gasto, como será evidenciado más adelante con tan solo algunas muestras, tenemos la posibilidad jurídica para encontrar los mecanismos que señala el doctor Juan Carlos de Obeso (2020: 149), materializado en el expediente amparo 293/2020 2A, radicado en el Juzgado Segundo de Distrito con sede en Mexicali.

Dicho juicio de garantías, bajo una tutela jurisdiccional efectiva y el derecho humano a la salud, activó los mecanismos citados de forma histórica, concediendo la suspensión a la parte quejosa, priorizando redireccionar el gasto a la pandemia SARS-CoV-2 sobre otros proyectos del gobierno federal, como «la refinería de dos bocas; tren maya; aeropuerto Felipe Ángeles; corredor transístmico; programa social jóvenes construyendo el futuro e ingresos por extinción de fideicomisos y mandatos públicos». ${ }^{6}$

A causa de lo anterior, es decir, del modelo gubernativo actual y el capricho del Estado, atentando en contra de la «idoneidad de la intervención pública y efectividad en los resultados - así como- la regulación y la calidad institucional como los medios que componen las herramientas de los modelos de Estado regulador y Estado garante» (Roldán Xopa, 2018), ${ }^{7}$ presentaron una queja, ahora sí bajo la perspectiva de un Estado de derecho y, al mismo tiempo, sin respetar este.

La queja citada fundamentalmente señalaba la ilegalidad de la decisión judicial al constituirle al justiciable un derecho a su favor, que no lo tenía antes del juicio constitucional, es decir, la reasignación a su favor del Presupuesto de Egresos de la Federación, debido a que no está constitucionalmente tutelada esta figura jurídica, no importando la necesidad de soportar un sistema de salud insuficiente ante la pandemia SARS-CoV-2.

6. Martín Méndez Pineda, «Concede juez amparo para canalizar recursos de obras federales a emergencia Nacional de covid-19», Infobaja, 13 de abril de 2020, disponible en bit.ly/2KADY8g.

7. Forma parte de las conclusiones del texto, tituladas «Estado regulador y Estado garante». 
Por parte de la ciudadanía, la violación principal pasa por el hecho de que, no obstante, «estas obras son muy importantes para el país, pero, por el momento, no son una prioridad. Por esto, los recursos federales deberían destinarse para la adquisición de materiales médicos y todo lo relacionado con la batalla en contra del covid-19», ${ }^{8}$ decisiones en que el ciudadano no pretende ir en contra del Estado en general, pero sí en contra de lo resuelto en un determinado caso en específico.

Dicha toma de decisiones, que al tiempo, como la evidencia lo demuestra, resultan más costosas para el ciudadano e incluso hasta confiscatorias al pagar elevados costos que no se deberían cubrir con una correcta planeación, además, de todos los órganos políticos que pueden corregir esto, los tiempos demandan la participación ciudadana directa no para satisfacer caprichos, sino para coexistir en la esencia constitucional del artículo 39:

Ahora, con respecto a la solicitud del quejoso consistente en la reasignación del presupuesto de egresos para el presente ejercicio, a efecto de que sea destinado a la crisis económica derivada de la emergencia nacional SARS-CoV2 (covid-19), es dable precisar que es procedente, ya que, de conformidad con el artículo 126 de la Constitución Política de los Estados Unidos mexicanos, el referido presupuesto no debe ser estricto, inflexible ni imposible de modificar. ${ }^{9}$

De acuerdo con la cita que hace Zoffoli (2010: 75), se señala que Habermas, hablando acerca del modelo cooperativo, menciona que «requiere la inclusión de todos los interesados directamente, los cuales producen un consenso motivado recurriendo a razones públicas defendidas por ellos mismos. En otros términos, lo que hay que valorizar en un modelo inclusivo de democracia participativa».

Por lo que el principio de «destino al gasto público» dentro de la justicia tributaria puede describirse en relación con que «dicho destino es el que justifica, junto con el principio de solidaridad, el desprendimiento patrimonial para dar sostén al aparato estatal y lograr la redistribución de la riqueza» ${ }^{10}$ pero bajo la necesidad ciudadana de satisfacer las prioridades no individuales, sino prioridades colectivas necesarias.

Como señala Hernández Guijarro (2016: 161), «la justicia como valor superior de todo ordenamiento jurídico y principio general del derecho ha sido una constante a lo largo de la historia de las ciencias jurídicas». En la justicia tributaria, es que «todos

8. Martín Méndez Pineda, «Concede juez amparo para canalizar recursos de obras federales a emergencia Nacional de covid-19", Infobaja, 13 de abril de 2020, disponible en bit.ly/2KADY8g.

9. Martín Méndez Pineda (véase nota anterior) hace referencia al auto admisorio del amparo 293/2020A, radicado en el juez segundo de distrito de Baja California, con sede en Mexicali, publicado en ese artículo de prensa.

10. Tesis de la Suprema Corte de Justicia de la Nación P. LXI/2011 (9. $\left.{ }^{a}\right)$ del 8 de septiembre de 2011, «Depósitos en efectivo. El Impuesto Relativo no viola el principio de destino al gasto público (Legislación publicada en el Diario Oficial de la Federación el 1 de octubre de 2007)». Adoptada por el Pleno en Sentencia Amparo en revisión 282/2009. Productos Europeos del Sureste, S.A. de C.V., disponible en bit. ly/3hmcQGb. 
contribuirán al sostenimiento de los gastos públicos de acuerdo con su capacidad económica mediante un sistema tributario justo, inspirado en los principios de igualdad y progresividad que, en ningún caso, tendrá alcance confiscatorio» (Hernández Guijarro, 2016: 161)

Por lo tanto, con base en el problema planteado acerca de la falta de un recurso o derecho constitucional que faculte al ciudadano para redireccionar el gasto público en México, le corresponderá al Poder Judicial ante dicha ausencia, bajo el principio de tutela jurisdiccional efectiva, evolucionar nuestra Constitución para generar el recurso judicial que sirva para tutelar las libertades de sus gobernados.

Es por esto que ante la ineficiencia descrita, no solo en la toma de decisiones en la ejecución del gasto público, sino en la pasividad de nuestros representantes en el Congreso y en las auditorías superiores, tanto a nivel estatal como federal, el propio ciudadano, que debería ser el actor principal, queda en una burda interdicción a merced de sus tutores ya citados, quienes deciden los presupuestos sobre bases poco claras en ocasiones y los gobernados han de someterse, sin más, a dichas decisiones.

Lo anterior deja en evidencia que las personas tienen un papel pasivo en la conformación de los presupuestos públicos, hasta en tanto no exista un reconocimiento constitucional que otorgue la posibilidad de intervenir activamente. Cierto es que la ejecución del gasto público, al materializarse, puede provocar actuaciones irregulares del Estado que pueden controvertirse a través de la Ley Federal de Responsabilidad Patrimonial del Estado, pero tales actuaciones son ex post a la ejecución de los presupuestos, y dependen más de una actuación irregular que de una asignación previa de los recursos públicos. Esa impugnación ex ante a la conformación de los presupuestos públicos es lo que constituiría un verdadero avance democrático y sobre la cual se discute a continuación, tanto para evidenciar errores en asignaciones presupuestales como para justificar la implementación de una solución jurídica al respecto.

\section{Algunos ejemplos de ineficiencia del gasto público en Jalisco}

El proyecto «Los Arcos del Tercer Milenio», obra creada con la finalidad de conmemorar la llegada del siglo XXI, ha sido, por el contrario, generadora de mayores costos a la administración en turno. En palabras del director del Sistema Intermunicipal de los Servicios de Agua Potable y Alcantarillado (SIAPA), Carlos Enrique Torres Lugo, por medio de esta obra se buscaba «la adecuación del sistema de captación pluvial existente para mitigar posibles inundaciones o encharcamientos en una sobrecarga de agua pluvial en la zona». ${ }^{11}$ Esta obra, a la fecha, continúa inconclusa.

En evidencia de lo mencionado en el párrafo anterior, incluso podemos encontrar lo expuesto en el sexto informe del gobernador de Jalisco, Aristóteles Sandoval, emanado en 2018 , con respecto a la inversión adicional realizada en un proyecto que empezó su

11. «Ampliará SIAPA infraestructura en Glorieta Arcos del Milenio», SIAPA, 28 de junio de 2019, disponible en bit.ly/34LyoZn. 
construcción en 1999 y que, casi 20 años después, sigue representando un gasto como consecuencia de una mala planeación y eficiencia. Como reflejo de lo anterior, se puede observar lo planteado en el cuadro informativo del Programa Integral de Manejo de Inundaciones (PIMI) del Gobierno Regional de Jalisco:

Esta obra mitiga las inundaciones del paso deprimido en la avenida Lázaro Cárdenas a su cruce con Mariano Otero, mediante una inversión de \$38’573,209.21 (son treinta y ocho millones quinientos setenta y tres mil doscientos nueve pesos 21/100 m.n.), dicha inversión justificada para evitar los cierres y colapsos viales que, en otros años, afectaban la zona y a miles de automovilistas (Sandoval, 2018: 25). ${ }^{12}$

En el análisis de los autores, este proyecto que empezó su construcción en 1999, con una inversión inicial en materiales, procesos de ensamble, pago de nóminas de los constructores, entre otros, aunado a problemáticas de cimentación. Al igual que en el ejemplo anterior, incrementaron el presupuesto y planeación original, más mano de obra y pintura para favorecer la obra, además de los incrementos ordinarios de la materia prima como el acero. Este proyecto, después de varias modificaciones y de múltiples suspensiones, se inauguró en 2007 , pero aún sin estar concluido, ya que solamente contaba con 4 de los 6 arcos que contemplaba la obra de forma inicial.

Con base en dicha obra, esta política no terminó en el 2000, ya que «formaba parte de una política de relanzamiento del arte urbano en la ciudad $»^{13} \mathrm{y}$, actualmente, 20 años después, a pesar de los más de 60 millones gastados, ha significado un gasto ineficiente que en nada ha contribuido a la rectoría del desarrollo social establecida en el artículo 25 de la Constitución, mucho menos en el párrafo III del artículo 1 del mismo ordenamiento.

Asimismo, al plantear este trabajo, hablamos desde nuestra perspectiva y ante la evidencia histórica, que no se puede hablar de eficiencia en una obra en la cual no se ha cumplido con el trabajo encomendado tanto en los términos como en las condiciones propuestas y "planeadas», haciendo más costoso el proyecto con cargo al erario y, por ende, a los ciudadanos, toda vez que se trata de una obra que debió culminar hace veinte años.

Otro ejemplo de esta falta de planeación en pro de la rectoría del desarrollo social, que impactó también al Estado de Jalisco, es uno de los proyectos más costosos nunca concretado. Se trata de la construcción de la Presa de Arcediano, al fondo de la Barranca de Huentitán, pensada para solucionar el abasto de agua para la metrópoli y en la que se invirtieron casi mil millones de pesos tan solo en estudios e indemnizaciones:

La Presa Arcediano, que nunca se construyó, tuvo un costo cercano a los mil millones de pesos y, a la fecha, no hay claridad sobre el destino de los recursos. La Comisión Nacional del Agua (Conagua) respondió una solicitud de información en la que con-

12. En este documento se muestra la inversión que se hizo para los Arcos del Milenio, derivado de las inundaciones y correcciones que se hicieron en su estructura.

13. Jaime Barrera, «De los Arcos del Milenio a los ¿Arcos 20-20?», Informador.mx., 15 de marzo de 2019, disponible en bit.ly/3ruZGvb. 
firma que de 2003 a 2009 encontró cheques o recibos por el envío de recursos a Jalisco por 473.9 millones de pesos (mdp), de los cuales $238 \mathrm{mdp}$ fueron para este proyecto. $\mathrm{Al}$ monto anterior, se suma la inversión de más de $673.4 \mathrm{mdp}$, que se utilizaron de un crédito estatal para abasto de agua. ${ }^{14}$

No obstante, en este proyecto, la Auditoría Superior de la Federación advirtió el inadecuado aprovechamiento de recursos, pero en los anales históricos no figura sanción que corrija dichas prácticas, solamente señalamientos por la ineficiencia en gasto o clasificaciones negativas, como la de ser el Estado de Jalisco el primer lugar nacional en dependencia de las participaciones federales.

No obstante dichas erogaciones, al gasto se sumaron otros 20 millones de pesos, utilizados en la reconstrucción del Puente de Arcediano después de que la Comisión Nacional de Agua determinara que, por el costo, la presa no era viable. Adicionando a lo anterior, la Auditoría Superior de la Federación detectó que, como se mencionó en el párrafo anterior, existía un inadecuado aprovechamiento de recursos.

Por otra parte, y de acuerdo con la evidencia hasta este momento plasmada, podríamos citar otros casos en Jalisco, como el rastro conocido como del tipo «TIF» en Acatlán de Juárez, con un gasto de más de 550 millones y una deuda actual de 300 millones de pesos que al momento sigue sin funcionar, ${ }^{15}{ }^{16} \mathrm{o}$ bien, la ciudad agropecuaria en el municipio de Tlaquepaque, ${ }^{17} \mathrm{o}$ las Villas Panamericanas que, con la anticipación del evento deportivo, tan solo dejó un gasto de 350 millones de pesos (SEPLAN, 2013). ${ }^{18}$

Estos datos no solo son ejemplos o antecedentes históricos económicos del gasto, sino que son, desde la perspectiva de los autores, una serie de inadecuadas planeaciones y un ejercicio del gasto ineficiente al ser más costoso para el ciudadano dado que los proyectos estimados solamente para ser realizados en determinada temporalidad, o bien no se culminen, dejando altos costos, o bien algunos llegan a postergarse excesivamente, como el caso citado de los «Arcos».

14. Sonia Serrano Iñiguez, «Tiran casi mil millones en la Presa Arcediano», El Diario NTR, 10 de febrero de 2020 , disponible en bit.ly/2JmALc1.

15. Jorge Velasco, «Deuda de 300 MDP atora al Rastro Metropolitano», Informador.mx., 19 de mayo de 2020, disponible en bit.ly/2LihdtW.

16. Leticia Rivera, «Abandonan rastro de $\$ 700$ millones», Reforma, 9 de febrero de 2018, disponible en bit.ly/34JiTPU.

17. «Tiran 755 MDP en «elefantes blancos» agropecuarios», Informador.mx., 23 de octubre de 2019, disponible en bit.ly/2LihlcU. En este documento, se observa información con respecto a la Ciudad Agropecuaria, proyecto desechado por el gobierno estatal de Jalisco.

18. En este punto, se hace referencia al reporte que dio la Secretaría de Hacienda Pública del Gobierno de Jalisco (SEPLAN) sobre las Villas Panamericanas y a la información sobre la base de inversión. SEPLAN (2013), Banco de Proyectos en Ejecución BPE-Construcción de la Av. El Bajío, para el ingreso de las Villas Panamericanas, col. el Bajío, en el municipio de Zapopan, en Guadalajara, Jalisco, disponible en bit.ly/34MubD8. 


\section{Referencias empíricas comparadas}

Ahora bien, para dar un panorama internacional en cuanto al planteamiento total de esta investigación, citamos un par de experiencias comparadas, tomando en cuenta que, en el caso mexicano en general, y de Jalisco en particular, la problemática de redireccionar el gasto en un contexto federalista, y en cuanto a sus antecedentes más recientes, ha sido el de recurrir en la esfera jurisdiccional a través de un derecho público subjetivo. Sin embargo, existen países en que esto se ha logrado a través de procesos democráticos, por medio de esquemas que pueden ser promovidos por los ciudadanos y que involucran decisiones sobre los recursos públicos presupuestados.

Ejemplo de esto es Francia, específicamente el pueblo de Arfons, de muy escasa población y que actualmente se encuentra inmerso en un contexto de bonanza después de quintuplicar en solo tres años su presupuesto gracias a un parque eólico instalado en su área. En efecto, este "pasó de 400.00o euros (alrededor de US\$520.000) en 2009 a 2,3 millones de euros (aproximadamente US $\$ 3$ millones) en la actualidad, según le dijo a la BBC el alcalde de la ciudad Alain Couzinié». ${ }^{19}$

Lo interesante del motivo por el que citamos este acontecimiento y/o este aspecto fenomenológico, se debe a que, en un contexto distinto al vivido en México o algunos países de Latinoamérica, como Brasil o Venezuela (por mencionar algunos), la clase política optó por la consulta popular en un ejercicio democrático y de claro dinamismo ciudadano a través del referéndum para que los residentes presentaran sus ideas y deseos de mejoras a su ciudad. ${ }^{20}$

En el párrafo anterior se observa, como muestra esa circunscripción geográfica francesa, que a través del diálogo y la complicidad directa de la población y el gobierno no solo se logra la satisfacción de los gobernados ante la consulta popular, sino una verdadera participación ciudadana en la decisión del gasto público. Cabe reconocer, eso sí, que se trata de una población de un poco más de ciento ochenta mil habitantes y que, comparados con un país de más de ciento veinte millones, en este último caso, se tiene que acudir, en este sentido, a un recurso legal, debido a la complejidad de implementar una consulta popular, lo anterior considerando la diversidad de preferencias y necesidades de la población mexicana.

Otro caso, por ejemplo, es el de la ciudad de Ichinomiya, ubicada en la prefectura de Aichi en Japón, con una población de 384.242 habitantes (incluidos 6.806 extranjeros). (Ciudad de Ichinomiya, 2020). Si solo contásemos con esos antecedentes, no habría un punto de comparación suficiente entre ella y el Estado de Jalisco o México, lo cual se vería reforzado con que, además, Japón es una monarquía constitucional parlamentaria y México es una república federal. No obstante, en 2008, sus ciudadanos establecieron un programa denominado «Programa de apoyo del 1\%», el cual, de forma esencial,

19. «El pueblo francés que no sabe cómo gastar su dinero», BBC News, 1 de mayo de 2013, disponible en bbc.in/3prHu3 $\mathrm{O}$.

20. Véase nota anterior. 
«busca incluir a la ciudadanía en el modo en el que se utilizan sus propios impuestos, aunque sea solo con el $1 \%$ de estos». ${ }^{21}$

¿Cómo se hace? Lo primero es calcular cuánto sería, más o menos, lo que corresponde al 1\% de los impuestos de la gente. Para esto, lo que hicieron fue considerar el número de habitantes de 18 años o más, y que puedan ejercer su derecho a voto. Después, contemplaron el $1 \%$ del monto total recibido en la prefectura por concepto de recaudación de impuestos [...]. Así, se dividió el número de personas por el 1\% del dinero recaudado. Por ejemplo, en 2016, cada persona pudo decidir qué hacer con 640 yenes (US\$ 5.7 dólares o CLP\$3.500) al año. Es muy poquito, sí, pero, sumando el monto de cada ciudadano, se pudieron tomar grandes decisiones. ${ }^{22}$

Al respecto, población y gobierno alcanzaron consensos mediante procesos participativos para asignar, desde la conformación del presupuesto, el destino mismo de los recursos, es decir, como una actuación ex ante y no ex post al diseño y ejecución de los presupuestos públicos que es como ha ocurrido y ocurre en Jalisco.

Por otra parte, debe considerarse el análisis que Rosa María Cañete efectuó en 2018 con base en la Encuesta de Presupuesto Abierto 2017, que realiza el International Budget Partnership y en la cual se considera a países constituidos como Repúblicas presidenciales, como Bolivia, Chile, Colombia, Costa Rica, República Dominicana, Ecuador, El Salvador, Guatemala, Honduras, Nicaragua, Paraguay y Perú o a Repúblicas presidenciales federales como Argentina, Brasil, México y Venezuela, entre otros.

En dicho trabajo se cita, en alusión al tema expuesto en este artículo, a un mecanismo digital de captación de preferencias de la ciudadanía desarrollado por medio de una plataforma digital, denominado Dataigualdad, la cual realiza una labor meramente informativa en cuanto al fomento de una decisión ciudadana participativa con respecto a la exacción de impuestos y el contrato social para la devolución de servicios por parte del Estado a sus ciudadanos acorde a las preferencias de la colectividad, y que, para el caso de México, no ha resultado ante la problemática expuesta:

Dataigualdad contiene más de 70 indicadores con datos sobre impuestos, gasto social, democracia, corrupción, transparencia, participación y garantía de derechos como salud, educación y vivienda de 18 países de América Latina y el Caribe, desde 1990 a 2016. Permite visualizar, descargar y exportar datos, y compartirlos en redes sociales de forma sencilla y amigable. Esta plataforma, única en Latinoamérica, impulsa el análisis de la fiscalidad desde una perspectiva de derechos y de participación ciudadana, y no como un ámbito meramente técnico o especializado. ${ }^{23}$

21. Rodolfo Westhoff, «¿Ciudadanos deciden en qué gastar sus impuestos? El curioso caso en Japón», El Definido, 26 de diciembre de 2017, disponible en bit.ly/3aKkyIM.

22. Véase nota 19.

23. Rosa María Cañete, «El bien común y los impuestos, algo más que un debate técnico en América Latina y El Caribe», El País, 29 de agosto de 2018, disponible en bit.ly/38RH5RF. 
También es importante destacar la necesidad de mecanismos legales y formales para efectos de fortalecer la participación ciudadana y, más aún, que ella no solo ocurra a través de este tipo de mecanismos digitales, que si bien es cierto que vinculan al ciudadano con su gobierno en este desempeño digital, han sido insuficientes ante las grandes brechas de desigualdad en estos países, ya que "América Latina y el Caribe no necesitan Estados más pequeños, sino más fuertes y más eficientes en la garantía de derechos». ${ }^{24}$

Continuando con la experiencia latinoamericana, y considerando la evidencia de la necesidad de mecanismos formales dentro de los derechos de los contribuyentes, en la tesis de Ingrid Katherine Zapata Gil (2019) se plantea la importancia de contar con un mecanismo como el de la objeción fiscal, que más que redireccionar el gasto como planteamos los autores, llama a la desobediencia civil en el pago de la contribución, ya que «se debe comprender la objeción fiscal como un proceso democrático e inherentemente político, que constituye un ejercicio de incidencia desde la ciudadanía en el conjunto de imágenes, valores, actitudes y practicas sobre los deberes fiscales» (Zapata Gil, 2019: 10). Lo anterior, a partir:

De una perspectiva de derechos humanos y de derecho tributario, con el objetivo de explorar las posibilidades de desarrollo práctico y jurídico, potenciando su reconocimiento y ejercicio como derecho tributario de los contribuyentes del impuesto de renta y complementarios en Colombia (Zapata Gil, 2019: 2).

Esto muestra que no es suficiente saber solamente mis necesidades de inversión pública como ciudadano, sino que, en caso de no hacerse apropiadamente esta última, la población se ve limitada a redireccionar o revertir la decisión política, económica y financiera del gobernante en turno.

Es decir, si bien es cierto que, por lo menos, bajo las ópticas abordadas en este capítulo se aprecian esbozos y la pretensión de un nuevo modelo en la fiscalidad y el trato de los ingresos, ya sea por medio de la desobediencia o de mecanismos legales formales para el contribuyente y/o el gobernado en general, salvo los ejemplos citados al inicio de este apartado, existen antecedentes y/o experiencias que manifiestan de forma implícita la necesidad de un recurso para el ciudadano en el redireccionamiento del gasto ante la ineficiencia de este en casos específicos.

\section{Conclusión}

Al haber examinado y juzgado un segmento de la justicia tributaria en esta investigación, y desde la perspectiva del destino del gasto público en México, a través de una metodología de investigación descriptiva, con base a los acervos periodísticos, leyes, y bibliografía pertinente a la ineficiencia administrativa, datos institucionales y criterios jurisprudenciales, y a partir de un análisis constitucional sistematizado, concluimos que si bien es cierto que el artículo 31, fracción IV de la CPEUM establece la obligación

24. Véase nota anterior. 
de los mexicanos a contribuir al gasto público de la República para que el Estado dote de servicios a sus ciudadanos en contraprestación de tal exacción, el artículo 35, fracción IV, también constitucional, de igual forma establece la obligación de los ciudadanos mexicanos de defender la República.

La tributación y el gasto público deben proporcionar libertad real, entendiendo por esta libertad no sólo aquella relativa al derecho a hacer lo que uno puede querer hacer, sino contar con los medios para poder hacerlo (Arteaga Mac Kinney, 2010: 105). Con base en lo anterior, y hasta el momento, los ciudadanos mexicanos, ante cualquier irregularidad que se observe en el desempeño de la función pública, podemos acudir a las instancias de transparencia respectivas. Lo mismo en caso de que hayamos sido afectados por alguna actividad irregular administrativa a la responsabilidad patrimonial del Estado o, incluso, como ciudadanos dentro de la actividad económica de coordinación fiscal, podemos intervenir con el recurso de inconformidad del artículo 11-A de la ley de la materia.

No obstante, con respecto al punto de partida de la administración en sí, que son los recursos con los cuales poder operar, esto es, aquellos que aportan los mexicanos, al parecer al Estado está conteste con la fórmula actual, en la cual el ciudadano es un ente pasivo que solamente vota y contribuye. Así, no lo dota para que se haga presente ante la pasividad de nuestros representantes en la Cámara o en los diversos órganos de vigilancia. Por ejemplo:

Lo que cuenta para Rousseau no es el contenido moral de las leyes, sino su génesis republicana. Solo si los ciudadanos están realmente incluidos en los procedimientos democráticos, podrán aceptar como legítima la estructura iuspolítica del Estado (Zoffoli, 2010: 75).

Es decir, no solo trasciende en una mala o buena ejecución del gasto o cualquier tipo de decisión, sino que se convierte en un tema de legitimidad.

Con base en lo anterior, el ciudadano carece de un recurso que fortalezca la igualdad. Como cita Arteaga Mac Kinney (2010: 106), no hay un «criterio normativo» para determinar la justicia de «las porciones normativas» (siguiendo a John Rawls en su obra Teoría de la Justicia) o asegurar la igualdad entre los seres humanos en tanto personas morales que tienen intereses irreductibles, intereses de «orden superior».

En efecto, el tránsito de un sistema político sin competencia hacia uno de corte democrático no garantiza mejores condiciones de vida para la población en general, entre otras cosas porque la participación de la ciudadanía, en diferentes ámbitos de la vida pública, es prácticamente nula (Valverde Viesca, Gutiérrez Márquez y García Sánchez, 2013).

Es decir, además de que el ciudadano se ha mantenido pasivo ante problemas como la toma de decisiones en la ejecución del gasto público, al amparo del mandato constitucional de nuestros diputados, ha provocado un rezago en la rectoría del desarrollo nacional dispuesto en el artículo 25 CPEUM, y la igualdad que debería de permear de acuerdo con el primer dispositivo de la ley fundamental también. 
Ante este contexto, se concluye que la ausencia de un derecho constitucional que faculte al ciudadano para redireccionar el gasto público no solo violenta la rectoría del desarrollo nacional y el principio de igualdad, sino que deja al Poder Judicial la oportunidad de hacer valer el principio de la tutela jurisdiccional efectiva como derecho público subjetivo para casos particulares que demanda el ciudadano.

Ahora bien, en relación con lo expuesto, puede observarse que, para lograr el cumplimiento del principio de tutela jurisdiccional efectiva en cuanto derecho humano, y siguiendo incluso la tesis aislada emitida por el Cuarto Tribunal Colegiado de Circuito del Centro Auxiliar de la Tercera Región, con residencia en Guadalajara, Jalisco, en el amparo directo 730/2011, los juzgadores deben desarrollar la posibilidad del recurso judicial. $^{25}$

Asimismo, para limitar dicho derecho, deberá ser instituido en el orden normativo nacional mexicano. Además, «tendremos que revisar a la justicia de las instituciones por su contribución a resultados justos, que son determinados por su contribución a una justa distribución de derechos, oportunidades y recursos» (Arteaga Mac Kinney, 2010: 107) $)^{26}$ al no existir un derecho constitucional para los casos anotados. O bien, encaminarlos bajo la esencia de lo dispuesto en la propia Constitución con respecto a que:

La soberanía nacional reside esencial y originariamente en el pueblo. Todo poder público dimana del pueblo y se instituye para beneficio de este. El pueblo tiene, en todo tiempo, el inalienable derecho de alterar o modificar la forma de su gobierno (Constitución Política de los Estados Unidos Mexicanos, 1917: artículo 39).

O, en este caso, apelar a la tutela jurisdiccional efectiva. Es muy importante concluir, por parte de los autores de esta investigación, que no deberá ser un derecho irresponsable o a voluntad del ciudadano, que permita a un individuo perjudicar a una mayoría. Para este efecto, deberán delimitarse los casos específicos de excepción, incluso establecer topes financieros, pero los mecanismos que constitucionalmente se lleguen a establecer deberán tener como premisa alejar la conformación de los presupuestos públicos de temas políticos y acercarlo a temas socialmente útiles. Ejemplos existen en el mundo. Los mejores mecanismos son los que deben discutirse para lograr así la democratización en la ejecución presupuestal de recursos que, finalmente, son de todos y no de los gobernantes que los ejercen.

25. Tesis del Cuarto Tribunal Colegiado de Circuito del Centro Auxiliar de la Tercera Región 6K (10. $\left.{ }^{\mathrm{a}}\right)$ del 10 de noviembre de 2011, «Tutela jurisdiccional efectiva. Para lograr la eficacia de ese derecho humano los juzgadores deben desarrollar la posibilidad del recurso judicial». Adoptada en Amparo directo 730/2011. Banco Santander México, S.A., Institución de Banca Múltiple, Grupo Financiero Santander, por unanimidad de votos, con voto aclaratorio del Magistrado José de Jesús López Arias. Ponente: Jorge Humberto Benítez Pimienta. Disponible en bit.ly/2WNuysQ.

26. Corresponde a la traducción de un extracto de «Why social justice matters» de Brian Barry. 


\section{Referencias}

Arteaga Mac Kinney, Roberto (2010). «La justicia fiscal en el marco de la teoría de la justicia como equidad de John Rawls. La tributación ¿carga, obligación o donación?» Dilemata, 2 (4): 101-115. Disponible en bit.ly/3poZCLD.

Ciudad de Ichinomiya (2020), «Ichinomiya City formal site» Disponible en bit. ly/3hkpagL.

De Obeso Orendain, Juan Carlos (2020). El principio de vinculación al gasto público a la luz de los derechos humanos. México D.F.: Tirant Lo Blanch.

Hernández Guijarro, Fernando (2016). La justicia tributaria en el ordenamiento plural. Revista Boliviana de Derecho, 21: 156-173. Disponible en bit.ly/3mO GZPE.

Roldán Xopa, José (2018). La ordenación constitucional de la economía, del estado regulador al estado garante. Ciudad de México: Fondo de Cultura Económica.

Sandoval, Aristóteles (2018). Informe de Gobierno 2018. Informe de Resultados. Tomo I. Disponible en bit.ly/3nPQsap.

Valverde Viesca, Karla, Enrique Gutiérrez Márquez y Flor de María García Sánchez, (2013). «Presupuesto público sin participación ciudadana. La necesidad de un cambio institucional en México para la consolidación democrática». Revista Mexicana de Ciencias Políticas y Sociales, 58: 218. Disponible en bit.ly/2WLe4RQ.

Zapata GIL, Ingrid Karen (2019). «Objeción Fiscal ¿Un derecho de los contribuyentes en el sistema tributario de Colombia?». Trabajo de Grado por la Universidad Jorge Tadeo Lozano de Colombia. Disponible en bit.ly/2KQ4qdX.

Zoffoli, Enrico (2010). «ürgen Habermas: entre hechos y normas». Isonomía, 32: 699o. Disponible en bit.ly/3nOYOPT.

\section{Sobre los autores}

Héctor Iván Del Toro Ríos es Magíster en Relaciones Económicas Internacionales con énfasis en la Cooperación AL-UE de la Universidad de Guadalajara de México y profesor del Departamento de Economía del Centro Universitario de Ciencias Económico Administrativas (CUCEA) de la misma casa de estudios. Su correo electrónico es hectorivan.deltoro@gmail.com. (D) https://orcid.org/0000-0001-8443-7581.

Hiram Zambrano Brambila es Doctor en Estudios Fiscales por la Universidad de Guadalajara de México y ejerce como profesor del Departamento de Ciencias Sociales y Jurídicas del Centro Universitario de Ciencias Económico Administrativas de la Universidad de Guadalajara de México. Su correo electrónico es hiram.zambrano@cucea. udg.mx. (D): https://orcid.org/0000-0001-5640-6585.

Ricardo Ruiz García es Maestro en Derecho Fiscal por la Universidad del Valle de México y es doctorando en Estudios Fiscales por el Centro Universitario de Ciencias Económico Administrativas de la Universidad de Guadalajara de México. Su correo electrónico es ricardo.ruiz5101@alumnos.udg.mx. (D) https://orcid. org/0000-0003-0210-7998. 
La Revista de Derecho Público es publicada desde 1963 por el Departamento de Derecho Público de la Facultad de Derecho de la Universidad de Chile. Aparece dos veces al año. Su propósito es la difusión de los avances del derecho público nacional e internacional y la socialización de artículos de investigación inéditos de la comunidad académica nacional e internacional.

DIRECTORA

Ana María García Barzelatto

SECRETARIO DE REDACCIÓN

Felipe Peroti Díaz

fperoti@derecho.uchile.cl

SITIO WEB

revistaderechopublico.uchile.cl

CORREO ELECTRÓNICO

publico@derecho.uchile.cl

LICENCIA DE ESTE ARTÍCULO

Creative Commons Atribución Compartir Igual 4.o Internacional

La edición de textos, el diseño editorial

y la conversión a formatos electrónicos de este artículo

estuvieron a cargo de Tipográfica

www.tipografica.io 